\title{
A Study on Various Home-Based Strategies to Strengthen Immunity Against Covid-19
}

\author{
P. Veena, DR.G. Benerjee, CH Krishna \\ Department of Zoology, Kakathiya University \\ District: Warangal, State: Telangana, Country: India
}

\begin{abstract}
The immune system plays a central role in protecting against infection, but due to its complexity and therefore the multiple ways during which it deals with viruses, the best advice is to consume a healthy, diverse, and well-balanced diet which can provide the nutrients required to understand a healthy gut microbiome, which can also benefit the system. The nutrients we get from food especially plant-based food like fruits, vegetables, herbs, and spices are essential to keeping our system functioning properly. For instance, research shows that spices like Clove, Oregano, thyme, cinnamon, and cumin contain antiviral and antimicrobial properties. The increased intake of turmeric, coriander, and garlic also improve our system, they have strong antioxidants and antiviral properties. Furthermore the zinc, folate iron, Selenium, copper, and vitamins A, C, E, B6, and B12 we get from food or helps in the system. We should maintain a healthy lifestyle of exercise, meditation, and regular sleep. Adequate sleep will help to support immune functioning. Simply going for a daily stroll or sneaking during a Yoga class a couple of times a week will keep our body physically fit and help the system. However good food practices are always recommended by the subsequent them and minimize the danger of contamination maintain proper hygiene, wash vegetables and fruits before eating wash rinse, and disinfect objects and surfaces whenever before and after use. keep cooked foods to stop harmful microbes. Consume unsaturated fats found in fish, nuts, soy, vegetable oil canola, vegetable oil, and sunflower instead of saturated fats found in butter fatty, meat coconut, and Palm oils, cheese, ghee, and cream. We should drink 8 to 10 glasses of water every day. To maintain effective stress reduction techniques keep our system healthy. Avoid alcohol and cigarette smoking also help our system.
\end{abstract}

Keywords: Immune system, antoxidants, anti-viral properties.

\section{INTRODUCTION}

The immune system consists of organs, cells, tissues, and proteins. Together, these perform bodily processes that repel pathogens, which are the viruses, bacteria, and foreign bodies that cause infection or disease. When the system comes into contact with a pathogen, it triggers an immune reaction. The system releases antibodies, which attach to antigens on the pathogens and kill them. Incorporating specific foods into the diet may strengthen a person's immune reaction. Read on to get 15 foods that boost the system.

The immune system is the body's defense mechanism. It forms the second line of defense, after physical barriers just like the skin and therefore the mucous membranes. It is located throughout the body and includes the thymus, the spleen, bone marrow, and a huge network of lymph nodes. It is made from many cells, proteins, tissues, and organs. The main function of the system is to stop and fight infection. A good system is important for the correct functioning of the body. A weakened system can cause symptoms like frequent sickness, allergies, fatigue, digestive issues, delayed growth, and slow development. A low immune function is often thanks to emotional stress, sleep deprivation, vitamin deficiencies, lack of workout, overexposure to harmful ultraviolet (UV) sunrays, excessive use of antibiotics, exposure to environmental toxins, poor dietary habits, and inadequate hygiene. Boosting the immune system is possible through lifestyle changes and some simple home remedies as recommended by Ayurveda. The metabolic activity of immune cells is enhanced after a viral infection, such as the one driven by COVID-19. Dietary approaches that support a healthy gut microbiome can benefit the system and ensure an honest nutritional status that might help the host affect pathogens. Although the system is usually working to stop pathogens from invading the body, also as eliminating those pathogens and generating an immunological memory, the metabolic activity of immune cell types is enhanced following a virus infection like COVID-19. That heightened activity is amid a better demand of energy and nutrients, which come from diet, to satisfy the immune cells' requirements. In a new comprehensive review, Prof. Philip Calder from the University of Southampton provides an update on the role of nutrition in supporting the system as a part of the present fight against COVID-19. 


\section{IARJSET}

\section{International Advanced Research Journal in Science, Engineering and Technology}

Vol. 8, Issue 6, June 2021

DOI: $10.17148 /$ IARJSET.2021.8629

\section{OBJECTIVES}

* To maintain physical health and mental health for strengthening the immune system.

* To maintain a healthy lifestyle and a balanced diet protect against infection.

* To study the various home-based strategies to strengthen immunity against covid-19.

* To maintain healthy habits protect against illness.

* To study the healthy and natural ways to strengthen our immune system against covid-19

* To develop natural immunity and protect our body against pathogens.

* To implement good healthy lifestyles and proper food habits protest against the infections.

* To depend on natural plant-based food protest against the illness and diseases

\section{HYPOTHESIS}

A diet will guarantee a robust system that will help withstand any assault by the virus. There is currently no evidence that any supplement can 'boost' our system and treat or prevent any viral infections, except vitamin C.

Vitamin $\mathrm{C}$ is one of the major constituents of water-soluble vitamins which tends to form a robust system. The daily recommended dietary allowance for Vitamin $\mathrm{C}$ is $90 \mathrm{mg} / \mathrm{d}$ for men and $75 \mathrm{mg} / \mathrm{d}$ for women. In the current situation, it's necessary to remember the precise sorts of food which will improve our system to combat COVID- Here are some professional and authentic dietary guidelines to face up to COVID-19.

- Eat fruits daily (guava, apple, banana, strawberry, cantaloupe melon, grapefruit, pineapple, papaya, orange, Longman fruit, blackcurrant, pummelo) with a serving size of two cups (4 servings).

- Eat fresh vegetables (green bell peppers, garlic, ginger, kale, lime, coriander (dried), broccoli, green chili pepper) 2.5 cups of vegetables ( 5 servings) legumes (beans and lentils).

- Eat whole grains and nuts, $180 \mathrm{~g}$ of grains (unprocessed maize, oats, wheat, millet, brown rice or roots such as yam, potato, taro, or cassava)

- Use nuts like almonds, coconut, and pistachio.

- Red meat can be eaten once or twice per week, and poultry 2-3 times per week. Use foods from animal sources (e.g. fish, fish, eggs, and milk) and $160 \mathrm{~g}$ of meat and beans.

- For snacks, choose fresh fruits and raw vegetables rather than foods that are high in sugar, salt, or fat. Avoid irregular snacking.

- Do not overcook vegetables as it leads to the loss of important nutrients such as vitamins and minerals.

- When using dried or canned fruits and vegetables, choose varieties without added sugar or salt.

- Make sure the food is prepared and served at acceptable temperatures $\left(72^{\circ} \mathrm{C}\right.$ for $\left.2 \mathrm{mins}\right)$.

- Limit the salt intake to five g a day.

- Consume unsaturated fats (found in avocado, fish, nuts, soy, olive oil, canola, corn oil, and sunflower) rather than saturated fats (found in butter, fatty meat, coconut, and palm oils, cheese, ghee, and cream).

- Drink 8-10 glasses of water every day. It helps to move nutrients within the blood, gets obviate waste, and regulates the blood heat.

- Avoid all fizzy, carbonated, concentrated juices, and all drinks which contain sugar.

- Maintain a healthy lifestyle of exercise, meditation, and regular sleep. Adequate sleep will help to support immune functioning.

- Eat at home to avoid contact with other people and try to reduce the chance of being exposed to COVID-19.

\section{METHODOLOGY}

Specific nutrients have the potential to modulate system activity through the gut microbiome. Different levels of evidence have shown the subsequent as key nutrients involved in reducing infection risk by supporting antibacterial and antiviral defense:

- Vitamins A, B6, B12, folate, C, D, and E,

- Trace elements including zinc, copper, selenium, and iron,

- Amino acids, and

- Fatty acids.

The mechanisms by which each of the nutrients named above support the system includes the strengthening of innate immune responses and antioxidant systems. Likewise, the gut microbiome also plays a task through its involvement in training the system and avoiding excessive inflammatory responses to pathogenic organisms. Furthermore, it is altered in patients with COVID-19.

Although zinc and selenium are shown to be particularly relevant for supporting antiviral defense, there's no single nutrient or diet which will prevent people from getting infected with SARS-CoV-2 or have an impact on mortality in 


\section{IARJSET}

\section{International Advanced Research Journal in Science, Engineering and Technology}

Vol. 8, Issue 6, June 2021

DOI: $10.17148 /$ IARJSET.2021.8629

COVID-19. The system plays a central role in protecting against infection, but thanks to its complexity and therefore the multiple ways during which it deals with viruses, the simplest advice is to consume a healthy, diverse, and wellbalanced diet which will provide the nutrients required to realize a healthy gut microbiome, which may also benefit the system.

Considering that some patients with COVID-19 are shown to possess an altered gut microbiome, including gastrointestinal symptoms, probiotics might be used as means of reducing bacterial translocation and secondary infection. However, albeit probiotics containing Lactobacillus and Bifidobacterium are shown to enhance immune function and enhance the response to some vaccinations, it's still early to conclude whether the gut microbiome plays a therapeutic role in preventing or treating COVID-19.

In some COVID-19 patients, an excessive inflammatory reaction (called a 'cytokine storm') can occur as a compensatory reaction by immune cells for handling lung damage. In that regard, Philip Calder acknowledges within the review that the polyunsaturated omega-3 fatty acids omega-3 fatty acid (EPA) and omega-3 fatty acid (DHA) seem to be relevant in resolving ongoing inflammatory processes in patients with an epidemic of severe acute respiratory distress syndrome.

A proper and healthy diet can ensure a strong system that will resist any onslaught by the virus. A certain amount of particular nutrient saturates into cells and prevents any quite nutritional deficiency. Individuals consuming wellbalanced diets appear to be safer with better immune systems and lower incidence of chronic diseases and infections. The main objective of this article is to induce healthy dietary habits that help to maintain the physical and mental health of individuals. The following nutrients help to strengthen our immune system.

\section{Citrus fruits:}

Most people turn straight to vitamin C after they've caught a chilly. That's because it helps build up your system. Vitamin $\mathrm{C}$ is thought to increase the production of white blood cells, which are key to fighting infections. Almost all citrus fruits are high in vitamin $\mathrm{C}$. With such a spread to settle on from, it's easy to feature a squeeze of this vitamin into any meal.

Popular citrus fruits include:

- grapefruit

- oranges

- clementines

- tangerines

- lemons

- limes

Because your body doesn't produce or store it, you would like daily vitamin C for continued health. The recommended daily amount for most adults is:

- $75 \mathrm{mg}$ for women

- $90 \mathrm{mg}$ for men

If you decide on supplements, avoid taking quite 2,000 milligrams ( $\mathrm{mg}$ ) each day. Also confine in mind that while vitamin C might assist you get over a chilly quicker, there's no evidence yet that it's effective against the new coronavirus, SARS-CoV-2.

\section{Red bell peppers}

If you think that citrus fruits have the foremost vitamin $\mathrm{C}$ of any fruit or vegetable, re-evaluate. Ounce for ounce, red bell peppers contain almost 3 times the maximum amount of vitamin $\mathrm{C}$ (127 mg) as a Florida orange (45 mg). They're also a rich source of beta carotene. Besides boosting your system, vitamin $\mathrm{C}$ may assist you to maintain healthy skin. Beta carotene, which your body converts into vitamin A, helps keep your eyes and skin healthy.

\section{Broccoli}

Broccoli is supercharged with vitamins and minerals. Packed with vitamins A, C, and E, as well as fiber and many other antioxidants, broccoli is one of the healthiest vegetables you can put on your plate. The key to keeping its power intact is to cook it as little as possible — or better yet, not in the least. Research has shown that steaming is that the best thanks to keeping more nutrients within the food.4. Garlic

Garlic is found in almost every cuisine within the world. It adds a touch of zing to food and it's a must-have for your health. Early civilizations recognized its value in fighting infections. Garlic can also hamper the hardening of the arteries, and there's weak evidence that it helps lower vital signs. Garlic's immune-boosting properties seem to return from an important concentration of sulfur-containing compounds, like allicin.

\section{Ginger}

Ginger is another ingredient much address after getting sick. Ginger may help decrease inflammation, which may help reduce pharyngitis and inflammatory illnesses. Ginger may help with nausea as well. While it's utilized in many sweet desserts, ginger packs some heat within the sort of gingerol, a relative of capsaicin. Ginger can also decrease chronic pain and might even possess cholesterol-lowering properties. 


\section{IARJSET}

\section{International Advanced Research Journal in Science, Engineering and Technology}

Vol. 8, Issue 6, June 2021

DOI: $10.17148 /$ IARJSET.2021.8629

\section{Spinach}

Spinach made our list not simply because it's rich in vitamin C - it's also full of numerous antioxidants and beta carotene, which can both increase the infection-fighting ability of our immune systems. Similar to broccoli, spinach is healthiest when it's cooked as little as possible so that retains its nutrients. However, light cooking makes it easier to soak up vitamin A and allows other nutrients to be released from ethanedioic acid, an antinutrient. Check out some spinach recipes here.

\section{Yogurt}

Look for yogurts that have the phrase "live and active cultures" printed on the label, like Greek yogurt. These cultures may stimulate your system to assist fight diseases. Try to get plain yogurts instead of the type that are flavored and loaded with sugar. You can sweeten plain yogurt yourself with healthy fruits and a drizzle of honey instead. Yogurt also can be an excellent source of vitamin D, so attempt to select brands fortified with this vitamin. Vitamin D helps regulate the system and is assumed to spice up our body's natural defenses against diseases. Clinical trials are even within the works to review its possible effects on COVID-19.

\section{Almonds}

When it involves preventing and fighting off colds, vitamin E tends to require a backseat to vitamin C. However, this powerful antioxidant is vital to a healthy system. It's a vitamin, which suggests it requires the presence of fat to be absorbed properly. Nuts, like almonds, are full of the vitamin and even have healthy fats. Adults only need about $15 \mathrm{mg}$ of vitamin E every day. A half-cup serving of almonds, which is about 46 whole, shelled almonds, provides around one hundred pc of the recommended daily amount.

\section{Sunflower seeds}

Sunflower seeds are filled with nutrients, including phosphorous, magnesium, and vitamins B-6 and E. Vitamin $\mathrm{E}$ is vital in regulating and maintaining system function. Other foods with high amounts of vitamin E include avocados and dark leafy greens. Sunflower seeds are also incredibly high in selenium. Just 1 ounce contains nearly half the selenium that the typical adult needs daily. A variety of studies, mostly performed on animals, have checked out its potential to combat viral infections like swine influenza (H1N1).

\section{Turmeric}

You may know turmeric as a key ingredient in many curries. This bright yellow, bitter spice has also been used for years as an anti-inflammatory in treating both osteoarthritis and atrophic arthritis. Research shows that prime concentrations of curcumin, which provides turmeric its distinctive color, can help decrease exerciseinduced muscle damage. Curcumin has promise as an immune booster (based on findings from animal studies) and an antiviral. More research is needed.

\section{Green tea}

Both green and black teas are full of flavonoids, a kind of antioxidant. Where tea excels is in its levels of epigallocatechin gallate (EGCG), another powerful antioxidant. In studies, EGCG has been shown to reinforce immune function. The fermentation process tea goes through destroys tons of the EGCG. Green tea, on the opposite hand, is steamed and not fermented, therefore the EGCG is preserved. Green tea is additionally an honest source of the aminoalkanoic acid L-theanine. L-theanine may aid in the production of germ-fighting compounds in your $\mathrm{T}$ cells.

\section{Papaya}

Papaya is another fruit loaded with vitamin C. You can find double the daily recommended amount of vitamin $\mathrm{C}$ during a single medium fruit. Papayas even have a digestive enzyme called papain that has anti-inflammatory effects. Papayas have decent amounts of potassium, magnesium, and folate, all of which are beneficial to your overall health.

\section{Kiwi}

Like papayas, kiwis are naturally filled with plenty of essential nutrients, including folate, potassium, vitamin K, and vitamin C. Vitamin C boosts the white blood cells to fight infection, while kiwi's other nutrients keep the remainder of your body functioning properly.

\section{Poultry}

When you're sick and you reach for soup, it's quite just the consequence that creates you are feeling better. The soup may help lower inflammation, which could improve the symptoms of a chilly. Poultry, like chicken and turkey, is high in vitamin B-6. About 3 ounces of sunshine turkey or chicken meat contains nearly one-third of your daily recommended amount of B-6. Vitamin B-6 is a crucial player in many of the chemical reactions that happen within the body. It's also vital to the formation of the latest and healthy red blood cells. Stock or broth made by boiling chicken bones contains gelatin, chondroitin, and other nutrients helpful for gut healing and immunity.

\section{Shellfish}

Shellfish isn't what jumps to mind for several who try to spice up their system, but some sorts of shellfish 


\section{IARJSET}

\section{International Advanced Research Journal in Science, Engineering and Technology}

Vol. 8, Issue 6, June 2021

DOI: 10.17148/IARJSET.2021.8629

are full of zinc. Zinc doesn't get the maximum amount of attention as many other vitamins and minerals, but our bodies need it so that our immune cells can function as intense varieties of shellfish that are high in zinc include:

- oysters

- crab

- lobster

- mussels

Keep in mind that you don't want to have more than the daily recommended amount of zinc in your diet:11 mg for adult men $8 \mathrm{mg}$ for most adult women too much zinc can inhibit immune system function. Washing hands properly may help make the immune system stronger.

The following lifestyle strategies may make a person's system stronger:

- avoiding smoking

- exercising regularly

- maintaining a healthy weight

- avoiding alcohol or drinking in moderation

- getting enough sleep

- minimizing stress

- practicing correct hand-washing and oral hygiene

How to Boost Your system Naturally

According to the Harvard school of medicine, to function well, our immune systems require balance and harmony. Here are several ways to market that balance through diet, exercise, supplements, and other healthyliving

strategies.

\section{1] Remember your A-B-C-D-Es.}

A scarcity of micronutrients - i.e., vitamins - has been linked to reduced immunity. Taking a multivitamin supplement, alongside eating a healthy diet rich in natural sources of nutrients, boosts overall health also because of the system. especially, vitamins A, B2, B6, C, D, and E are studied about an immune reaction and appear to play a key role in helping us avoid illness.

2] Get some sun.

Spending a while in natural light is one of the key ways our bodies manufacture vitamin D . vitamin D plays a task in helping our immune systems produce antibodies; low levels of vitamin D, on the opposite hand, are correlated with a better risk of respiratory tract infection.

3] Open your mouth and say "om."

While the physical effects of stress are still being studied by scientists, studies have thus far proven that chronic stress can cause a spread of negative effects on physical and emotional well-being, including a reduced immune reaction. Stress-reducing practices like meditation, massage, and even music can help us relax and improve our immune function.

4] Try turmeric.

The brilliant orange-yellow spice that provides curries a definite flavor and mustard its color also have antiinflammatory properties, and there's increasing evidence that it helps prevent illness, too. Particularly relevant for seniors, extracts of turmeric seem to play a task in preventing cancer, slowing Alzheimer's, and alleviating arthritis pain.

5] Run a soothing bath.

A pleasant hot bath, with Epsom salt or relaxing aromatherapy scents, can go an extended way toward reducing our stress - and making us sleepy. Sleep is one of the key ways our bodies repair themselves, and sleep deprivation, reports Mother Earth News, "activates the strain response, depresses immune function and elevates inflammatory chemicals."

\section{6] Eat more vegetables.}

Vegetables, also as fruits, nuts, and seeds, are loaded with nutrients that we'd like to stay our immune systems in top health. especially, cruciferous vegetables like cabbage, kale, and broccoli help support liver function, a key part of our bodies natural detoxification process.

\section{7] Micromanage your minerals.}

Additionally, to a variety of vitamins, it's important to urge enough — but not an excessive amount of — of key minerals that are important to daily health. Selenium, consistent with the Harvard school of medicine, may help prevent cancer, and zinc may be a critical ingredient for the right function of our immune cells. However, experts caution that an excessive amount of zinc can impair immune function, so it's important to stay to the 


\section{IARJSET}

\section{International Advanced Research Journal in Science, Engineering and Technology}

Vol. 8, Issue 6, June 2021

DOI: $10.17148 /$ IARJSET.2021.8629

recommended daily allowance.

8] make space for 'shrooms.

Certain sorts of mushrooms, particularly Japanese mushrooms like shiitake, maitake, and oyster mushrooms, have recently been shown to assist support the assembly of immune cells. They're also loaded with antioxidants. 9] Try herbal remedies.

Scientists are still studying the effectiveness of the many herbal supplements traditionally used as health boosters, like echinacea and ginseng, but whether or not they need a measurable effect on the system, a soothing tea can help with relaxation, sleep, and stress reduction. Of course, you ought to always ask a doctor before making herbal treatments a daily part of your arsenal.

10] boost your cooking.

Pungent but tasty garlic and ginger are both delicious, immune-boosting additions to the family diet. Raw garlic especially contains antimicrobial and cancer-fighting agents, and ginger has been used for hundreds of years in traditional medicine to treat nausea, colds, and flu symptoms.

\section{1] keep it up moving.}

Regular exercise contributes to our overall health in numerous ways, and a healthy body means a smoothly functioning system. Some sorts of exercise, like t'ai chi and yoga, also are particularly fitted to reducing stress and improving the strength, balance, and adaptability that we frequently lose as we age.

\section{2] Consider taking probiotics.}

Probiotics, or "good" bacteria, aren't only a crucial part of a healthy digestive process but also our immune systems, though scientists are still studying exactly how and why this happens. A study on athletes found that probiotic supplements helped prevent and combat colds, but you'll also get probiotics from naturally fermented food sources, like yogurt and kimchi.

Boosting your family's immunity doesn't need to be a chore it is often delicious, relaxing, and fun. Just confirm to consult a doctor before beginning any major changes to your regimen, and don't forget those medical tests and flu shots, especially for senior loved ones.

\section{Eat a Healthy Diet}

The nutrients you get from food - especially, plant-based foods like fruits, vegetables, herbs, and spices — are essential to keeping your system functioning properly, consistent with Yufang Lin, MD, an integrative medicine doctor at Cleveland Clinic in Ohio. "Many plant-based foods even have antiviral and antimicrobial properties, which help us repel infection

For example, research shows that spices like clove, oregano, thyme, cinnamon, and cumin contain antiviral and antimicrobial properties that prevent the expansion of food-spoiling bacteria like Bacillus subtilis and Pseudomonas fluorescens, harmful fungi like Aspergillus flavus, and antibiotic-resistant microorganisms like Staphylococcus aureus, consistent with a review published in June 2017 within the International Journal of Molecular Sciences. Furthermore, the zinc, folate, iron, selenium, copper, and vitamins A, C, E, B6, and B12 you get from the food you eat are the nutrients your system must do its job, consistent with the Academy of Nutrition and Dietetics. all play a singular role in supporting immune function.

Research suggests, for instance, that vitamin C deficiency may increase the likelihood of infection, consistent with a review published November 2017 in Nutrients. Our bodies don't produce this essential, vitamin on their own, so we'd like to urge it through foods (such as citrus fruits, kiwis, and many other cruciferous vegetables). you'll get 95 milligrams (mg), or 106 percent of the daily vitamin $\mathrm{C}$ you would like by snacking on a half-cup of red pepper, consistent with the NIH.

Protein is additionally critical for immune health. The amino acids in protein help build and maintain immune cells, and skimping on this macronutrient may lower your body's ability to fight infections. In one study published February 2013 within the Journal of Infectious Diseases, mice who ate a diet consisting of only 2 percent protein were more severely impacted by the flu than mice who ate a "normal protein" diet with 18 percent protein. But once researchers started feeding the primary A "normal protein" diet, the mice were ready to get obviate the virus. When it involves a diet that supports good immune health, specialize in incorporating more plants and plant-based foods. Add fruits and veggies to soups and stews, smoothies, and salads, or eat them as snacks, Lin says. Carrots, broccoli, spinach, red bell peppers, apricots, citrus fruits (such as oranges, grapefruit, tangerines), and strawberries are all great sources of vitamins $\mathrm{A}$ and $\mathrm{C}$, while seeds and nuts will provide protein, vitamin $\mathrm{E}$, and zinc, consistent with the Academy of Nutrition and Dietetics.

Additional sources of protein and zinc include seafood, lean meat, and poultry, consistent with the Academy of Nutrition and Dietetics. 


\section{IARJSET}

\section{International Advanced Research Journal in Science, Engineering and Technology}

Vol. 8, Issue 6, June 2021

DOI: $10.17148 /$ IARJSET.2021.8629

\section{Ways to stay Your system Healthy}

\section{Laugh a touch (or a lot).}

Binge-watching until the wee hours of the night isn't recommended, but a couple of episodes of your favorite funny show are beneficial. A 2007 study found that laughter is that the best medicine: It can give your immunity a ridiculously easy boost.

Laughing -- and an overall happy, positive attitude -- lowers stress levels and may promote sleep, arguably two of the foremost crucial elements to a healthy body. And, admit it, it's probably the foremost fun you will have giving your system a lift.

\section{Keep Stress in check}

According to a review published within the October 2015 issue of Current Opinion in Psychology, long-term stress results in chronically elevated levels of because steroid cortisol. The body relies on hormones like cortisol during short-term bouts of stress (when your body goes into a "fight-or-flight" response); cortisol features a beneficial effect of truly preventing the system from responding before the stressful event is over (so your body can react to the immediate stressor). But when cortisol levels are constantly high, it essentially blocks the system from kicking into gear and doing its job to guard the body against potential threats from germs like viruses and bacteria. There are many effective stress-reduction techniques; the key's to seek out what works for you. "I wish to give my patients options," says Ben Kaplan, MD, an indoor medicine physician at Orlando Health Medical Group general medicine in Florida. He recommends meditation (apps like Headspace and Calm can help), journaling, and any activity that you simply enjoy (such as fishing, playing golf, or drawing). attempt to do a minimum of one stressreducing activity a day. Short on time? Start small. put aside five minutes at some point every day for fun and increase it once you can.

\section{Get much Good Quality Sleep}

Your body heals and regenerates while you sleep, making adequate sleep critical for a healthy immune reaction, Lin says.

More specifically, sleep may be a time when your body produces and distributes key immune cells like cytokines (a sort of protein that will either fight or promote inflammation), $\mathrm{T}$ cells (a sort of white blood corpuscle that regulates immune response), and interleukin 12 (a pro-inflammatory cytokine), consistent with a review published in Pflugers Archiv European Journal of Physiology.

When you don't get enough sleep, your system might not do this stuff also, making it less ready to defend your body against harmful invaders and making you more likely to urge sick. One study published within the July-August 2017 issue of Behavioral Sleep Medicine found that compared with healthy young adults who didn't have sleep problems, otherwise healthy young adults with insomnia were more vulnerable to the flu even after getting vaccinated. Sleep deprivation also elevates cortisol levels, which is additionally not good for immune function, Lin says. "Our system wears down as a result, and that we tend to possess [fewer] reserves to repel or get over the illness." The National Sleep Foundation recommends all adults get a minimum of seven hours of sleep per night to optimize health. to make sure you get quality sleep, prioritize good sleep hygiene: close up the electronics a minimum of two to 3 hours before bed, and avoid violent or stressful books or conversations, Lin says.

\section{Exercise Regularly (Outdoors, When Possible)}

Regular exercise lowers your risk of developing chronic diseases (like obesity, type 2 diabetes, and heart condition ), also as viral and bacterial infections, consistent with a review in Frontiers in Immunology in April 2018. Exercise also increases the discharge of endorphins (a group of hormones that reduce pain and make feelings of pleasure) making it an excellent thanks to managing stress. "Since stress negatively impacts our system, this often differently exercises can improve immune reaction," Lin says.

And while there's some evidence that very long or intense exercise sessions may suppress the system, making you more vulnerable to illness and infection within the hours immediately after your workout, the evidence thereon question is contradictory, consistent with an equivalent Frontiers in Immunology review. And there's a wealth of epidemiological evidence (studies that followed human behavior and outcomes) showing that folks who are more active overall tend to possess lower incidences of both acute illnesses (like infections) and chronic ones (like cancer and sort 2 diabetes). Studies that have checked out how exercise affects the body on a cellular level suggest that bouts of physical activity may make your system more vigilant by distributing immune cells throughout your body to seem for damaged or infected cells, consistent with that 2018 report.

At a minimum, attempt to meet the physical activity guidelines outlined by the Centers for Disease Control and Prevention (CDC). Adults should be accessed at least 150 minutes (two and a half hours) of moderateintensity aerobics (like walking, jogging, or cycling) or 75 minutes (one hour and 15 minutes) of highintensity aerobics (like running) hebdomadally. you ought to even be doing strength training a minimum of twice every week. Note: More activity is linked to even more health benefits, so aim high. 


\section{IARJSET}

\section{International Advanced Research Journal in Science, Engineering and Technology}

Vol. 8, Issue 6, June 2021

DOI: $10.17148 /$ IARJSET.2021.8629

For even more system benefits, Dr. Kaplan recommends taking your exercise outside. Spending time in nature has been shown to support mood, lower vital signs, reduce inflammation, and support system health, consistent with Lin. Sunshine also boosts vitamin D within the body, which plays a key role in immune health, too.

\section{When It involves Alcohol, Practice Moderation}

Drinking high amounts of alcohol is related to a variety of negative health effects, including lowered immune function. once you drink high amounts of alcohol, your body is just too busy trying to detoxify your system to bother with normal system function, Kaplan explains.

According to a review published within the journal Alcohol Research in 2015, high levels of alcohol consumption can weaken your body's ability to fight infection and hamper your recovery time. As a result, people that drink high amounts of alcohol face a greater likelihood of pneumonia, acute respiratory distress syndrome, alcoholic disease, and certain cancers, consistent with an equivalent review.

If you don't already drink, don't start. If you drink occasionally, limit your alcohol consumption to at least one drink (equivalent to a 4-ounce glass of wine) per day if you're a lady, and two drinks per day if you're a person, as recommended by the NIH.

\section{Don't Smoke Cigarettes}

Like alcohol, cigarette smoking also can affect immune health. "Anything that's a toxin can compromise your system," Kaplan says.

In particular, the chemicals released by cigarette smoke - carbon monoxide gas, nicotine, nitrogen oxides, and cadmium - can interfere with the growth and performance of immune cells, like cytokines, $\mathrm{T}$ cells, and $\mathrm{B}$ cells, consistent with a November 2016 review in Oncotarget.

Smoking also worsens viral and bacterial infections (especially those of the lungs, like pneumonia, flu, and tuberculosis), post-surgical infections, and atrophic arthritis (an autoimmune disorder during which the system attacks the joints), consistent with the CDC.

"Don't smoke," Lin says. And avoid secondhand smoke whenever possible.

If you currently smoke, there are many resources available to assist you to kick your habit, including counseling, nicotine replacement products, prescription non-nicotine medications, and behavioral therapy, consistent with the CDC.

\section{Keep Symptoms of Chronic Conditions in check}

Chronic conditions like asthma, heart disease, and diabetes can affect the system and increase the risk of infections. For example, when people with type 2 diabetes don't manage their blood glucose properly, this will create a chronic, low-grade inflammatory response that weakens the body's defense system, consistent with an October 2019 review in Current Diabetes Reviews.

Similarly, people with asthma are more vulnerable to catching — and even dying from - the flu, and sometimes experience worse flu and asthma symptoms as a result of the infection, consistent with a study published within the July 2017 issue of the Journal of Allergy and Clinical Immunology. Living with a chronic condition is often like trying to drive a car that has only three tires, Kaplan says. "If you get sick with an epidemic, it's getting to take more effort for your body to recover," he explains. If you manage your chronic conditions better, you'll release more reserves to assist your body to repel infection, Lin says. So make certain to remain on top of any medications, doctor visits, and healthy habits that keep your symptoms cornered.

\section{CAUSES OF LOW IMMUNITY}

\section{Stress:}

Stress affects everyone at some point in our lives. The hallmarks of stress are headaches, pounding chest pains, uneasiness, and an overall tense feeling. With in the presence of stress, the system has got to work harder to defend the body against health threats. Stress can suppress the system to such an extent that it's severely compromised.

\section{Not enough exercise:}

Our system cannot function well if our lifestyle is sedentary. Regular exercise can help the function of neutrophils. These cells can help kill disease-causing germs which will negatively affect health.

\section{Lack of sleep:}

While sleeping, the cells within the blood fight infections and keep them cornered. So lack of sleep and fatigue can leave you susceptible to infection.

\section{Improper nutrition:}

It is important to eat a well-balanced assortment of foods including fruits, vegetables, and whole-grain sources. These foods support the system by providing crucial vitamins, minerals, phyto chemicals, and antioxidants. Fatty junk foods should be avoided. Fats, especially polyunsaturated fats, tend to suppress the system. Sugar can inhibit phagocytosis, the method by which white blood cells work to destroy viruses and bacteria. 


\section{IARJSET}

\section{International Advanced Research Journal in Science, Engineering and Technology}

Vol. 8, Issue 6, June 2021

DOI: $10.17148 /$ IARJSET.2021.8629

\section{CONCLUSION}

A diet will guarantee a robust system that will help withstand any assault by the virus. there's currently no evidence that any supplement can 'boost' our system and treat or prevent any viral infections, except vitamin C. vitamin C is one of the main constituents of water-soluble vitamins which tends to form a robust system. The daily recommended dietary allowance for vitamin $\mathrm{C}$ is $90 \mathrm{mg} / \mathrm{d}$ for men and $75 \mathrm{mg} / \mathrm{d}$ for ladies. within the current situation, it's necessary to remember the precise sorts of food which will improve our system to combat COVID-19. Here are some professional and authentic dietary guidelines9 to face up to COVID-19:

A proper diet can help to make sure that the body is within the strongest possible state to battle the virus. The food safety management system must provide food safety officials and workers with proper personal protective equipment to avoid contamination.10,7 Researchers have found that there's no source of virus contamination via food packaging or food. However, good food practices are always recommended by following them to attenuate the danger of contamination which are as follows:

- nutrient saturates into cells and prevents any quite nutritional deficiency. Individuals consuming well-balanced diets appear to be safer with better immune systems and lower incidence of chronic diseases and infections. the most objective of this text is to induce healthy dietary habits that the Specific nutrients have the potential to modulate system activity through the gut microbiome

Different levels of evidence have shown the subsequent as key nutrients involved in reducing infection risk by supporting antibacterial and antiviral defense:

- Vitamins A, B6, B12, folate, C, D, and E,

- Trace elements including zinc, copper, selenium, and iron,

- Amino acids, and

- Fatty acids.

The mechanisms by which each of the nutrients named above support the system includes the strengthening of innate immune responses and antioxidant systems. Likewise, the gut microbiome also plays a task through its involvement in training the system and avoiding excessive inflammatory responses to pathogenic organisms. Furthermore, it's been shown to be altered in patients with COVID-19.

\section{To take care of the physical and psychological state of people.}

1. Don't smoke.

2. Eat a diet high in fruits and vegetables.

3. Exercise regularly.

4. Maintain a healthy weight.

5. If you drink alcohol, drink only carefully.

6. Get adequate sleep.

7. Take steps to avoid infection, like washing your hands frequently and cooking meats thoroughly.

$\square$ Drink warm water throughout the day.

$\square$ Practice Meditation, Yogasana, and Pranayama.

$\square$ Increase the intake of Turmeric, Cumin, Coriander, and garlic.

$\square$ Drink herb tea or decoction of Holy basil, Cinnamon, Black pepper, Dry Ginger, and Raisin.

$\square$ Avoid sugar and replace it with jaggery if needed.

Apply Ghee (clarified butter), vegetable oil, or copra oil in both nostrils to stay the nostrils clean.

$\square$ Inhale steam with Mint leaves and Caraway seeds.

\section{REFERENCES}

[1]. Bogoch II, Watts A, Thomas-Bachli A, Huber C, Kraemer MU, Khan K. Pneumonia of unknown etiology in Wuhan, China: potential for international spread via commercial air travel. J Travel Med. 2020;272:1-3. [PMC free article] [PubMed] [Google Scholar]

[2]. Ksiazek TG, Erdman D, Goldsmith CS, Zaki SR, Peret T. Emery S, Tong S, et al., editors. A novel coronavirus associated with the severe acute respiratory syndrome. $N$ Engl J Med. 2003;348(20):1953-1966. [PubMed] [Google Scholar]

[3]. Aslam MF, Majeed S, Aslam S, Irfan JA. Vitamins: Key role players in boosting up the immune response, A mini-review Vitam. Miner. 2017;6:153. [Google Scholar]

[4]. Yousafzai AK, Rasheed MA, Bhutta ZA. Annual research review: improved nutrition-a pathway to resilience. $J$ Child Psychol Psychiatry. 2013;54:367-377. [PubMed] [Google Scholar]

[5]. Gleeson M, Nieman DC, Pedersen BK. Exercise, nutrition, and immune function. J Sports Sci. 2004;22:115-125. [PubMed] [Google Scholar]

[6]. Macht M. How emotions affect eating: a five-way model. Appetite. 2008;50:1-11. [PubMed] [Google Scholar]

[7]. Anton SD, Miller PM. Do negative emotions predict alcohol consumption, saturated fat intake, and physical activity in older adults? Behav Modify. 2005;29:677-688. [PubMed] [Google Scholar]

[8]. Haug A, Brand-Miller JC, Christophersen OA, McArthur J, Fayet F, Truswell S. A food "lifeboat": food and nutrition considerations in the event of a pandemic or other catastrophe. Med J Aust. 2007;187:674. [PubMed] [Google Scholar]

[9]. Khayyatzadeh SS. Nutrition and Infection with COVID-19. J Nutr Food Security. 2020;5(2):93-96. [Google Scholar] 


\section{IARJSET}

\section{International Advanced Research Journal in Science, Engineering and Technology}

Vol. 8, Issue 6, June 2021

\section{DOI: $10.17148 / I A R J S E T .2021 .8629$}

[10]. Wypych TP, Marsland BJ, Ubags ND. The impact of diet on immunity and respiratory diseases. Ann Am Thorac Soc. 2017;14:339347. [PubMed] [Google Scholar]

[11]. Coronavirus disease 2019; (COVID-19)—Symptoms and causes.

[12]. Hui DS, I Azhar E, Madani TA, et al. The continuing 2019- nCoV epidemic threat of novel coronaviruses to global health-The latest 2019 novel coronavirus outbreak in Wuhan, China 2020. 3.

[13]. 13.International Journal of Infectious Diseases 2020; 91:264- 266

[14]. WHO Director-General's opening remarks at the media briefing on COVID-19. World Health Organization (WHO) (Press release.2020)

[15]. "COVID-19 Dashboard by the Center for Systems Science and Engineering (CSSE) at Johns Hopkins University (JHU)".

[16]. Boost your immunity against the Coronavirus-COVID-19, Risks of Infection | Narayana Health.

[17]. Maggini S. Feeding the immune system: the role of micronutrients in restoring resistance to infections. CAB Reviews: Perspectives in Agriculture, Veterinary Science, Nutrition and Natural Resources. 2008; 3:98.

[18]. Calder PC, Jackson AA. Undernutrition, infection, and immune function. Nutr Res Rev. 2000; 13:3-29.

[19]. News medical life science.

[20]. Levine, H. 5 Ways to Boost Your Immune System 2020.

[21]. Malter M, Schriever G, Eilber U Natural killer cells, vitamins, and other blood components of vegetarian and omnivorous men. Nutr Cancer. 1898; 12:271-78.

[22]. CarddockJC, Neale EP, People GE, et al. Vegetarian-based dietary patterns and their relation with inflammatory and immune biomarkers: A systematic review and meta-analysis. Adv Nutr. 2019; 10:433-451.

[23]. Rinninella E, Cantoni M, Raoul P, et al. Food components and dietary habits: keys for a healthy gut microbiota composition. Nutri. Published online October 7. 2019; 1-23.

[24]. SoldatiL, Di Renzo L, Jirillo E, et. al. The influence of diet on anti-cancer immune responsiveness. J Trans1 Med. 2018; 16:75-93.

[25]. Wood LG, Attia J, Mceldu FM P, et al. Assessment of dietary fat intake and innate immune activation as risk factors for impaired lung function. Eur J Clin Nutr. 2010; 64:818-825.

[26]. Rasmussen LB, Kiens B, Pedersen BK, et al. Effect of diet and plasma fatty acid composition on immune status in elderly men. Am J Clin Nutr. 1994; 59:572-577.

[27]. Alwarawrah Y, Kiernan K, MacIver NJ Changes in nutritional status impact immune cell metabolism and 6 Citation: Sunita Mishra, Monika Patel. Role of nutrition on the immune system during COVID-19 pandemic. J Food Nutr Health 2020 3(2). J Food Nutr Health 2020 Volume 3 Issue 2 function. Front Immunol. 2018; 9:1055-1069.

[28]. Haddad EH, Berk LS, Kettering JD, et al. Dietary intake and biochemical, hematologic, and immune status of vegans compared with nonvegetarians. Am J Clin Nutr. 1999; 70:586-93S.

[29]. Eichelmann F, Schwingshackl L, Fedirko V, et al. Effect of plant-based diets on obesity-related inflammatory profiles: a systematic review and meta-analysis of intervention trials. Obes Rev. 2016; 17:1067-1079.

[30]. Huang Z, Liu Y, Qi, et al. Role of Vitamin A in the Immune System. J Clin Med. 2016; 7:258.

[31]. The Role of Nutrition in the Immune System | Part I of IISight and Life.

[32]. Foods to Boost the Immune System

[33]. Rall LC and Meydani SN. Vitamin B6 and immune competence. Nutr Rev. 2016; 51:217-25.

[34]. Tamura J, Kubota K, Murakami H, et al. Immunomodulation by vitaminB12: augmentation of CD8 T lymphocytes and natural killer (NK) cell activity in vitamin B12-deficient patients by methyl-B12 treatment ClinExpImmunol. 1999; 116:28-32.

[35]. Mikkelsen K., Apostolopoulos Vitamin B12, Folic Acid, and the Immune System. In: Mahmoudi M., Rezaei N. (eds) Nutr and Immu. Springer, Cham 2019.

[36]. Hemilä H, Louhiala P. Vitamin C for preventing and treating pneumonia. Cochrane database of systematic reviews 2013; $100: 495-498$.

[37]. Grant WB, Lahore H, McDonnell S, et al. Evidence that vitamin D supplementation could reduce risk of influenza and COVID-19 infections and deaths. Nutr. 2020; 12:988.

[38]. Chung C, Silwal P, Kim I, et al. Vitamin D-cathelicidin axis: at the crossroads between protective immunity and pathological inflammation during infection. Immune Netw. 2020; 20:2-38.

[39]. Charan, J; Goyal JP; Saxena, et al. Vitamin D for prevention of respiratory tract infections: A systematic review and meta-analysis. J Pharmacol Pharmacother. 2012; 3:300-303.

[40]. Gysin DV, Dao D, Gysin CM et al. Effect of vitamin D3 supplementation on respiratory tract infections in healthy individuals: A systematic review and meta-analysis of randomized controlled trials. PloS one. 2016; 11 